\title{
Knowledge and Practices Regarding Self-Management of Minor Ailments among Pregnant Mothers
}

\section{Suduweli Koonge Sashanika Nishadi Samarakoon'), Fathima Farhana Habeeb Mohamed"), Kalanchi Mahadurage Shalitha Madushanka Wijerathnas), Gnanaselvam Kisokanth4)}

\author{
${ }^{1)}$ National Hospital, Kandy, Sri Lanka \\ 2)BSc Nursing Graduate \\ 3)National Hospital, Colombo, Sri Lanka \\ 4)Department of Clinical Nursing, Faculty of Nursing, University of Colombo, Sri Lanka
}

\section{ABSTRACT}

Background: During pregnancy, mother faces many minor discomforts due to physiological, anatomical, psychological, biochemical and immunological adaptations occurs in their body. The wellbeing of pregnant mothers is threatened due to these minor discomforts and lead to unnecessary hospitalization. This study was aimed to assess the knowledge and practices regarding self-management of minor discomforts among pregnant mothers attending to selected Antenatal Clinics (ANC), Medical Officer of Health (MOH) area, Batticaloa.

Subjects and Method: A cross sectional descriptive study was conducted in selected antenatal clinics among all registered antenatal mothers $(n=238)$ attending to these ANCs. A validated and pretested interviewer administered questionnaire was used to collect the data. Knowledge on self-management of minor disorders was dependent variable and independent variables were the sociodemographic status, economic status and obstetric details of pregnant mothers. Descriptive and inferential statistic was performed to analyze the relevant data.

Results: Nearly half of the participants (54.6\%) were in 20-29 years and 62\% of them were primiparous mothers. Around $93 \%$ of them were experienced nausea and vomiting during their pregnancy and among them all were reported nausea and vomiting has been occurred during their 1st trimester. About $75 \%$ of them mentioned that home remedies are the best way to selfmanage the minor discomforts. The mean knowledge score on minor discomforts and selfmanagement was $12.16(\mathrm{SD}=14.64)$. Majority of participants (94.1\%) scored less than 50\%. Knowledge score was significantly associated with participant's ethnicity, religion, monthly income, educational level and their parity.

Conclusion: The prevalence of minor discomforts among pregnant mothers was high and pregnant mothers have expressed that minor discomforts can be managed with home remedies. Further, knowledge level regarding minor discomforts and their self-management was inadequate.

Keywords: Antenatal mothers, minor discomforts, knowledge, self-management, Sri Lanka

\section{Correspondence:}

Gnanaselvam Kisokanth. Department of Clinical Nursing, Faculty of Nursing, University of Colombo, Sri Lanka. Email: kiso@dcn.cmb.ac.lk Mobile: +94772228330

\section{Cite this as:}

Samarakoon SKSN, Mohamed FFH, Wijerathna KMSM, Kisokanth G (2020). Knowledge and Practices Regarding Self-Management of Minor Ailments among Pregnant Mothers. J Matern Child Health. 05(03): 303312. https://doi.org/10.26911/thejmch.2020.05.03.09.

(c) (1) (-) Journal of Maternal and Child Health is licensed under a Creative Commons Attribution-Non Commercial-Share Alike 4.o International License.

\section{BACKGROUND}

Pregnancy is usually a time period of nine months which a woman carries a fetus (Arul- kumaran et al., 2011). During this period, many physiological, anatomical, psychological, biochemical and immunological adapta- 
tions happens within the mother and leads to many minor discomforts (Fraser and Cooper, 2011; Dutta, 2004). The wellbeing of pregnant mothers are threatened due to these minor discomforts (Latha and Indira, 2016).

National Institute for Care and Health Excellence (NICE) report in 2008 stated that minor discomforts are very common and reported by $50 \%$ - $80 \%$ of pregnant women (Aziz and Maqsood, 2017). During $1^{\text {st }}$ trimester, mostly nausea and vomiting, fatigue and frequency of micturition can be developed and most of these minor discomforts will be diminished during $2^{\text {nd }}$ trimester. But heart burn, constipation, vaginal discharge and mild back pain can be observed commonly in $2^{\text {nd }}$ trimester. Further, During $3^{\text {rd }}$ trimester, minor discomforts such as hemorrhoids, leg cramp, edema and varicosities can be developed (Latha and Indira, 2016).

Nausea and vomiting are the commonest symptoms consistently experienced in early pregnancy. A survey has reported that nausea affects between $70 \%$ and $85 \%$ of pregnant women and vomiting affects approximately 50\% of pregnant women (Jewell and Young, 2003). Nausea and vomiting occurs in $50-75 \%$ of all pregnancies during the first trimester (Jarvis and Nelson-Piercy, 2011). Reported prevalence rates of constipation during pregnancy have ranged from $9 \%$ to $39 \%$ (Bradley et al., 2007) and varicosities are also a common minor discomfort can be developed and the veins in the legs as well as vulva are most commonly affected during pregnancy (Maternal Care Package Sri Lanka, 2011). Approximately $40 \%$ of pregnant mothers develop varicosities during 2nd and 3 rd trimesters (Arulkumaran et al., 2011).

American Pregnancy Association in 2007 reported that 50\% to $70 \%$ of all pregnant women may have back pain (Aziz and Maqsood, 2017). In addition, heartburn and gastro esophageal reflux disease (GERD) are also common during pregnancy and the pre- valence reaches up to $25 \%$ of pregnant women (Bor et al., 2007). According to American Society for Nutrition in 2011, leg cramps have been reported up to $30 \%$ of pregnant women, most commonly in the second and third trimester (Aziz and Maqsood, 2017). Further, pelvic pain, urinary frequency, dysuria, urinary incontinence, swollen legs, dental decay, skin changes, tiredness and sleeplessness are also found to be the minor discomforts during pregnancy (Maternal Care Package Sri Lanka, 2011).

Non-pharmacological therapies can be considered as the first line treatment for minor discomforts, if appropriate. However, medication may be required to ensure the well-being of the mother and prevent secondary adverse effects to the fetus (Dhanawade, 2017). The high prevalence of these minor ailments has a major effect on productivity and profound impact on the lives of pregnant women and their families (Sangeetha et al., 2015).

Further, minor ailments affect the health of pregnant mother as well as fetus which affects physical and mental functions of both. In addition, minor ailments are the leading causes of productivity cost among Sri Lankan pregnant women (Agampodi et al., 2013). One of the WHO objective by 2020 is to promote healthy lifestyle in all people and even in pregnant mothers (Aziz and Maqsood, 2017). Thus, if pregnant mothers are helped to manage their minor discomforts, it effectively restores their health (Kaur and Gagandeep, 2017).

The minor discomforts of pregnancy would make difficulties for the health care provider as well as for the pregnant woman herself. Successful management of these minor discomforts requires adequate knowledge on minor ailments and its self-management. It is important for the mother to gain the knowledge to equip her to cope with the experience of pregnancy and also gain spe- 
cific knowledge, when she presents with a worrying symptom or discomfort.

Pregnant mothers can misinterpret these minor discomforts as pathological and it can also lead to unnecessary hospitalizations (Dutta, 2004). In order to avoid unnecessary cost and hospitalization, pregnant mothers possess good knowledge on minor discomforts and its self-management. Health care professionals would help pregnant mothers to distinguish physiological symptoms from pathological and offer advices and reassurance on these minor discomforts. In order to educate the pregnant mothers, the knowledge level and practice on minor discomforts and self-management need to be assessed.

There are no studies conducted in Batticaloa district up to date on knowledge and practices on minor discomforts and its selfmanagement among the pregnant mothers. Thus, this study was aimed to assess pregnant mother's knowledge level and practices on minor discomforts and its self-management in order to identify the areas that need more concern in educating the mothers for early detection and management of minor discomforts which help the mothers to avoid unwanted hospitalizations.

\section{SUBJECTS AND METHOD}

\section{Study Design}

This was a cross sectional study conducted among all registered pregnant mothers in selected antenatal clinics (ANC) of $\mathrm{MOH}$ area, Batticaloa. The selected ANCs were Puliyantheevu, Manjanthoduvai, Kalladyveloor, and Karuveppankerny where highest numbers of antenatal mothers were registered and following the clinic in Batticaloa $\mathrm{MOH}$ area.

\section{Population and Sample}

The population of this study were all primigravida and multigravida mothers who are willing to participate. Health care personal and mothers who having psychological disorders or physical discomforts were excluded from the study. A total of 238 pregnant mothers were included in the study i.e., Manjanthoduvai (76 mothers), Kalladyveloor (58 mothers), Karuveppankerny (64 mothers), and Puliyantheevu (40 mothers).

\section{Study Variables}

The dependent variable in this study was Knowledge on self-management of minor disorders among pregnant mothers. The independent variables in this study were the Sociodemographic status, economic status and obstetric details of pregnant mothers.

\section{Operational Definition of Variables} Maternal education was the highest formal education obtained by pregnant mother. Monthly income was the total amount of husband and wife's income earned for each month.

Knowledge level was assessed by giving marks for knowledge questions on the minor discomforts and its self-management as follows; One mark was given for each correct response and o was given for wrong or unknown responses for the knowledge questions on the minor discomforts and its selfmanagement practices. The total attainable score was 92 for the questionnaire. Then, the total score was converted to $100 \%$. The level of knowledge was categorized according to the marks range as follows; poor $-<50 \%$, adequate $-50-75 \%$ and good- $>75 \%$.

\section{Study Instruments}

The data were collected by using a judgmentally validated and pre-tested interviewer administered questionnaire by investigators under the guidance of supervisor.

\section{Data Analysis}

The data were double checked by the investigators and was entered into the SPSS V2O. Descriptive statistic was performed to analyze mean, percentage and other relevant details. The association between the socio-demographic factors and knowledge level was obtained by using chi-square test. p value, $<$ o.05 was considered as a significant. 
Samarakoon et al./ Knowledge and practices regarding self-management

\section{Research Ethics}

After getting the permission from all relevant authorities, investigators explained about nature and the purpose of the study to the participants using information sheet, and informed consent was obtained before the commencement of this study. The Ethical clearance was obtained from Ethics Review Committee, Faculty of Health-Care Sciences, Eastern University, Sri Lanka.

\section{RESULTS}

\section{Sample Characteristics}

Nearly half of the study participants (54.6\%) were in the age group of 20-29 years with a mean of $28.79(\mathrm{SD}=5.46)$ years. Almost all participants (99.6\%) were married. Majority were Tamil and Hindu. Nearly 30\% of participants had completed up to GCE (O/L). Nearly half (56.3\%) of the participants were unemployed. Monthly income of most of the participants (73.9\%) was between Rs. 10,00150,000. The mean monthly income was Rs. $43,386.13( \pm 30,673 \cdot 53)$. Nearly $62 \%$ of the participants were primigravida mothers. Most of the participants (62.2\%) were in their 3rd trimester (Table 1 ).

Almost all of the participants (97.9\%) stated that nausea and vomiting is the most common minor discomfort occurs during pregnancy. Further, nearly $42 \%$ of the mothers stated that backache is a pregnancy related minor discomfort (Table 2).

Table 1. Socio-demographic and obstetric characteristics of participants

\begin{tabular}{llcc}
\hline Socio-demographic & \multicolumn{1}{c}{ Characteristics } & Frequency (n) & Percent (\%) \\
\hline Age (years old) & $\leq 19$ & 10 & 4.2 \\
& $20-29$ & 130 & 54.6 \\
& $30-39$ & 86 & 36.1 \\
Ethnicity & $40-49$ & 12 & 5.1 \\
& Tamil & 187 & 78.6 \\
Religion & Muslim & 49 & 20.6 \\
& Burgher & 2 & 0.8 \\
Educational level & Hindu & 171 & 71.8 \\
& Islam & 49 & 20.6 \\
& Christianity & 18 & 7.6 \\
Family type & No schooling & 7 & 2.9 \\
Consanguinity & Primary education & 31 & 13.1 \\
Parity & GCE Ordinary level & 75 & 31.5 \\
Trimester & GCE Advance level & 73 & 30.7 \\
& Diploma / Degree & 52 & 21.8 \\
& Nuclear family & 112 & 47.1 \\
& Extended family & 126 & 52.9 \\
& Yes & 13 & 5.5 \\
& No & 225 & 94.5 \\
& Primigravida & 147 & 61.8
\end{tabular}

Most of the participants (92.9\%) were experienced nausea and vomiting during their pregnancy and reported that nausea and vomiting has been occurred during their 1st trimester. Nearly $41 \%$ of participants were experienced backache during their pregnancy and among them $91.8 \%$ were reported back- ache has been occurred during their 2nd trimester. Nearly half of the participants (57\%) mentioned that physical changes during pregnancy are the main cause for the minor discomforts during pregnancy and $30 \%$ of the study participants do not know any reason for the minor discomforts (Table 3 ). 
Samarakoon et al./ Knowledge and practices regarding self-management

Table 2. Known minor discomforts of pregnancy stated by participants

\begin{tabular}{lcc}
\hline \multicolumn{1}{c}{ Minor discomforts of pregnancy } & Frequency (n) & Percent (\%) \\
\hline Nausea and vomiting & 233 & 97.9 \\
Pica eating & 17 & 7.1 \\
Urinary frequency & 41 & 17.2 \\
Heart burn & 40 & 16.8 \\
Constipation and hemorrhoids & 22 & 9.2 \\
Backache & 99 & 41.6 \\
Leg cramps & 69 & 29.0 \\
Varicose vein & 44 & 18.5 \\
\hline
\end{tabular}

Table 3. Reported minor discomforts by participants during their current pregnancy

\begin{tabular}{|c|c|c|c|c|c|c|c|c|}
\hline \multirow{3}{*}{ Minor discomfort } & \multicolumn{2}{|c|}{ Among all } & \multicolumn{6}{|c|}{ Trimester } \\
\hline & \multirow{2}{*}{$\mathbf{n}$} & \multirow{2}{*}{$\%$} & \multicolumn{2}{|c|}{$\mathbf{1}^{\text {st }}$} & \multicolumn{2}{|c|}{$\mathbf{2}^{\text {nd }}$} & \multicolumn{2}{|c|}{$3^{\text {rd }}$} \\
\hline & & & $\mathbf{n}$ & $\%$ & $\mathbf{n}$ & $\%$ & $\mathbf{n}$ & $\%$ \\
\hline Nausea and vomiting & 221 & 92.9 & 221 & 100.0 & 40 & 18.1 & $\mathrm{O}$ & 0.0 \\
\hline Pica eating & 3 & 1.3 & 3 & 100.0 & $\mathrm{O}$ & 0.0 & $\mathrm{O}$ & 0.0 \\
\hline Urinary frequency & 53 & 22.3 & 52 & 98.1 & 36 & 67.8 & $\mathrm{O}$ & 0.0 \\
\hline Heart burn & 57 & 23.9 & 43 & 75.4 & 47 & 82.5 & $\mathrm{O}$ & 0.0 \\
\hline Constipation & 10 & 4.2 & 6 & 60.0 & 4 & 40.0 & $\mathrm{O}$ & 0.0 \\
\hline Backache & 97 & 40.8 & 8 & 8.2 & 89 & 91.8 & 52 & 53.6 \\
\hline Leg cramps & 62 & 26.1 & O & 0.0 & 58 & 93.5 & 37 & 59.7 \\
\hline Leg edema & 17 & $7 \cdot 1$ & 2 & 11.8 & 17 & 17.0 & 5 & 29.4 \\
\hline Varicose vein & 29 & 12.2 & O & 0.0 & 18 & 62.1 & 16 & 55.2 \\
\hline
\end{tabular}

Table 4. Self-management strategies on the minor discomforts

\begin{tabular}{llrc}
\hline Minor discomfort & \multicolumn{1}{c}{ Self-management strategies } & n & \% \\
\hline Nausea and & Avoid triggering food or activities cause vomiting & 111 & 47.6 \\
oomiting & Drink king coconut water & 74 & 31.8 \\
(n= 233) & Taking home remedies containing ginger & 71 & 30.5 \\
Pica eating & Take sour food variety & 155 & 66.5 \\
(n=17) & Using an alternative oral stimulant & 17 & 100.0 \\
& Maintaining a pica box & 14 & 82.4 \\
Urinary frequency & Taking nutritional supplements & 16 & 94.1 \\
(n=41) & Void before going to the bed & 28 & 68.3 \\
& Reduce fluid intake in late night & 6 & 14.6 \\
Heart burn & Proper positioning to reduce the pressure on bladder & 8 & 19.5 \\
(n= 40) & Eat small frequent meals & 7 & 17.5 \\
& Drink a glass of milk & 35 & 87.5 \\
Constipation and & Avoid eating excessively before going to bed & 4 & 10.0 \\
Hemorrhoids & Avoid hot, fatty and spicy foods & 29 & 72.5 \\
(n= 22) & Make sure you include plenty of fiber in your diet & 14 & 63.6 \\
Backache & Exercise regularly to keep your muscles toned up & 14 & 63.6 \\
(n= 99) & Make sure you drink plenty of water & 19 & 86.4 \\
& Avoid vigorous exercises & 36 & 36.4 \\
Leg cramps & Applying hot water sponging & 28 & 28.3 \\
(n= 69) & Avoid wearing high heels & 34 & 34.3 \\
& Sit with your back straight and well supported & 70 & 70.7 \\
& Take calcium supplements & 24 & 34.8 \\
& Increase walking & 41 & 59.4 \\
Varicose vein & Try to avoid standing for long period & 42 & 60.9 \\
(n= 44) & Put your feet up as much as you can & 38 & 55.1 \\
\hline & Try to do foot related simple exercises & 40 & 58.0 \\
& Do walking exercises & 35 & 79.5 \\
\hline
\end{tabular}


Samarakoon et al./ Knowledge and practices regarding self-management

Most of the participants (75\%) stated that home remedies are best way to manage their minor discomforts during pregnancy and $25 \%$ of the participants mentioned that hospitalization is better way to manage their minor discomforts. Most of the mothers (66.$5 \%)$ preferred to take sour food to relieve from nausea and vomiting. Nearly $88 \%$ of participants stated that drink a glass of milk is a good self-management strategy to relieve from heart burn. About $71 \%$ of participants sit with their back straight and well supported to manage their backache (Table 4).
The mean knowledge score on minor discomforts and its self-management was 12.16 (Mean=12.16; $\mathrm{SD}=14.64)$. Majority of participants $(94.1 \%, \mathrm{n}=224)$ scored less than $50 \%$ and $5.9 \%(n=14)$ scored $51-75 \%$ on minor discomforts and its self-management. Knowledge score was significantly associated with ethnicity $(\mathrm{p}=0.010)$, religion $(\mathrm{p}<0.001)$ and educational level $(\mathrm{p}<0.001)$. But there is no any significant association between the characteristics such as age, family type and consanguinity (Table 5).

\section{The result of bivariate analysis}

Table 5. The results of knowledge and practices regarding self-management of minor ailments among pregnant mothers (an analysis by Chi Square)

\begin{tabular}{|c|c|c|c|c|c|}
\hline \multirow{3}{*}{$\begin{array}{l}\text { Participants } \\
\text { characteristics }\end{array}$} & \multicolumn{4}{|c|}{ Knowledge } & \multirow{3}{*}{$\mathbf{p}$} \\
\hline & \multicolumn{2}{|c|}{ Poor } & \multicolumn{2}{|c|}{ Adequate } & \\
\hline & $\mathbf{n}$ & $\%$ & $\mathbf{n}$ & $\%$ & \\
\hline \multicolumn{6}{|l|}{ Age (years old) } \\
\hline$\leq 19$ & 10 & 4.4 & o & 0.0 & \multirow{4}{*}{0.171} \\
\hline $20-29$ & 119 & 53.1 & 11 & 78.6 & \\
\hline $30-39$ & 83 & 37.0 & 3 & 21.4 & \\
\hline $40-49$ & 12 & $5 \cdot 3$ & $\mathrm{O}$ & 0.0 & \\
\hline \multicolumn{6}{|l|}{ Ethnicity } \\
\hline Tamil & 181 & 80.3 & 6 & 42.9 & \multirow{3}{*}{0.013} \\
\hline Muslim & 41 & 18.3 & 8 & 57.1 & \\
\hline Burgher & 2 & 0.9 & o & 0.0 & \\
\hline \multicolumn{6}{|l|}{ Religion } \\
\hline Hindu & 165 & 73.7 & 6 & 42.9 & \multirow{3}{*}{$<0.001$} \\
\hline Islam & 41 & 18.3 & 8 & 57.1 & \\
\hline Christianity & 18 & 8.0 & o & 0.0 & \\
\hline \multicolumn{6}{|l|}{ Educational level } \\
\hline No schooling & 3 & 1.3 & 4 & 28.6 & \multirow{5}{*}{$<0.001$} \\
\hline Primary education & 31 & 13.8 & o & 0.0 & \\
\hline GCE Ordinary level & 75 & 33.5 & o & 0.0 & \\
\hline GCE Advance level & 68 & 30.3 & 5 & 35.7 & \\
\hline Diploma / Degree & 47 & 21.1 & 5 & $35 \cdot 7$ & \\
\hline \multicolumn{6}{|l|}{ Family type } \\
\hline Nuclear family & 108 & 48.2 & 4 & 28.6 & \multirow[t]{2}{*}{0.152} \\
\hline Extended family & 116 & 51.8 & 10 & 71.4 & \\
\hline \multicolumn{6}{|l|}{ Consanguinity } \\
\hline Yes & 13 & 5.8 & o & 0.0 & \multirow[t]{2}{*}{0.201} \\
\hline No & 211 & 94.2 & 14 & 100.0 & \\
\hline \multicolumn{6}{|l|}{ Monthly income (Rs.) } \\
\hline$<10000$ & 4 & 1.8 & o & 0.0 & \multirow{4}{*}{$<0.001$} \\
\hline $10001-50000$ & 167 & 74.6 & 9 & 64.3 & \\
\hline 50001-100000 & 51 & 22.8 & 0 & 0.0 & \\
\hline$>100000$ & 2 & 0.8 & 5 & $35 \cdot 7$ & \\
\hline \multicolumn{6}{|l|}{ Parity } \\
\hline Primigravida & 133 & 59.4 & 14 & 100.0 & \multirow[b]{2}{*}{0.001} \\
\hline Multipara & 91 & 40.6 & 0 & 0.0 & \\
\hline
\end{tabular}




\section{DISCUSSION}

During the period of pregnancy, women undergo a lot of physical and hormonal changes which cause the minor discomforts during pregnancy and are not life-threatening. A lot of these discomforts may be calm down in this pregnancy progress, but it causes inconvenience and stress to most of pregnant women (Sharif et al., 2018).

However, there are only a few studies are describing the relation between knowledge and its self-management of antenatal mothers regarding minor discomforts of pregnancy. The present study shows that nearly $4 \%$ of the participants were below 19 years and $5 \%$ of them were more than 40 years. If the pregnant women are below 18 years old or more than 40 years old, the pregnancy could be considered as "high-risk pregnancy". Women tend to have a window of time when it's easier on their body to grow a baby and give birth and to have a perfectly healthy pregnancy outside this window of time, as teenage pregnancy and advanced maternal age pregnancy tend to have more complications.

All most all mothers (92.9\%) had nausea and vomiting and nearly $20 \%$ of the mothers were experienced urinary frequency and heart burn during their 1st trimester. Further, backache (37.4\%) and leg cramps (24.4\%) were commonly found as minor discomforts during 2nd trimester among the participants. Nearly 20\% of the mothers were experienced backache and leg cramps during their 3 rd trimester of pregnancy. Contrast to this, a study conducted in Anuradhapura district Sri Lanka, found that more percent of women experienced minor discomforts such as $70 \%$ of study participants during their pregnancy experienced nausea and vomiting, back ache (32\%), dizziness (24\%), and heart burn (23\%) (Agampodi et al., 2013). Further, another study done at selected hospitals of Patiala, India showed that only $30 \%$ of the mothers experienced nausea and vomiting and constipation during their 1st trimester and 30\% of the mothers experienced backache during 2nd trimester and most of the mothers (62\%) had ankle edema during their 3rd trimester (Kaur and Gagandeep, 2017).

Study participants followed many selfcare management strategies to handle their minor discomforts during their pregnancy period. In the present study, almost $68 \%$ participants used to void before going to the bed to manage their urinary frequency and nearly $90 \%$ of participants mention that, avoid standing for long period to protect them from varicose vein. This nearly agrees with the findings of a study conducted at Saudi Arabia, almost 74\% of women used to void before going to the bed to manage their urinary frequency. But, contrast to our finding, nearly $12 \%$ of participants only prefer to avoid standing for long period to protect themselves from varicose vein (Sharif et al., 2018).

In the present study, $94.1 \%$ of the participants had poor knowledge and nearly $5 \%$ of the mothers had adequate knowledge on minor discomforts and it's self-management during pregnancy. Somewhat similar findings were found in a study reported that, $87 \%$ of antenatal mothers have inadequate level of knowledge regarding minor disorders of pregnancy (Alageswari and Dash, 2019). Contrast to this, a study done at Andhra Pradesh, India found that the level of knowledge on minor discomforts and it's self-management among pregnant women, $26.67 \%$ of participants had good knowledge, 33.33\% had average knowledge and 40\% had poor knowledge (Karnati and Vanaja, 2015).

In the present study, the knowledge level had significant association with religion ( $p<0.001)$, ethnicity $(\mathrm{p}=0.013)$, monthly income $(\mathrm{p}<0.001)$ and educational level $(\mathrm{p}$ $<0.001$ ) of the study participants. Similar to the present findings, a study conducted in 
2017 at Dammam city, Saudi Arabia among antenatal mothers revealed that there is a significant relationship between the knowledge level on minor discomforts with education $(\mathrm{p}=0.023)$ and monthly income $(\mathrm{p}=$ o.009) (Gamel et al.,2017). Further, a study carried out at Nelloor among pregnant mothers of urban area on knowledge regarding home management of minor discomforts found that there is a significant relationship between knowledge level with religion (Karnati and Vanaja, 2015).

In summary, all most all antenatal mothers had experienced nausea and vomiting and also less percentage of participants' experienced urinary frequency and heart burn during their 1st trimester. Further, backache and leg cramps were commonly found as minor discomforts during 2nd trimester among the participants. Most of the participants (75\%) stated that home remedies were the best way to manage their minor discomforts during pregnancy which $25 \%$ of them mentioned minor discomforts should be managed by hospitalization. Participants had obtained poor score on minor discomforts and self- management with the mean of 12.16 ( \pm 14.64$)$. Further majority of the participants had poor knowledge score $(<$ $50 \%)$ and nearly $5 \%$ of the mothers had adequate knowledge score (50-75\%) on minor discomfort and its self-management. Knowledge score on minor discomforts and its selfmanagement was significantly associated with participant's ethnicity, religion, educational level, monthly income and with the parity of participants.

This study recommends that all pregnant mothers must possess with good knowledge about minor discomfort and its selfmanagement in order to prevent unnecessary hospitalization. Therefore, healthcare professionals must arrange health education programmes focusing on minor discomforts and its self-management. Health care providers we must work with healthcare delivery system to ensure the access of high quality care and we must provide data and information to healthcare policy makers. Healthcare professionals must arrange educational programmes to the family members and community to provide information on pregnancy related minor discomforts and to have more concern about pregnant mothers.

\section{AUTHOR CONTRIBUTION}

Suduweli Koonge Sashanika Nishadi Samarakoon has designed the study; collect, analyzed, and interpreted the data. Fathima Farhana Habeeb Mohamed has designed the study; collect, analyzed, and interpreted the data. Kalanchi Mahadurage Shalitha Madushanka Wijerathna has also designed the study; collect, analyzed, and interpreted the data. Gnanaselvam Kisokanth designed the study, interpreted the data and wrote the manuscript. All have reviewed the manuscript.

\section{CONFLICT OF INTEREST}

There is no conflict of interest in this study.

\section{FUNDING AND SPONSORSHIP}

This study used personal funds from the all authors.

\section{ACKNOWLEDGEMENT}

Acknowledgments were conveyed by author to study participants. Authors are very grateful to the participants of this research. Also, Authors would like to express their thanks to Medical Officer of Health, Batticaloa, and Family Health Officer and Public Health Midwives who helped us a lot during our data collection.

\section{REFERENCE}

Agampodi SB, Wickramasinghe ND, Horton $\mathrm{J}$, Agampodi TC (2013). Minor ailments in pregnancy are not a minor concern for pregnant women: A morbidity 
Samarakoon et al./ Knowledge and practices regarding self-management

assessment survey in rural Sri Lanka. PLoS One. 8(5):1-6. https://doi.org/10.1371/journal.pone.0064214

Alageswari A and Dash MB (2019). Assessment of Knowledge and Expressed Practice Regarding Self-Management of Minor Aliments among Antenatal Mothers. Journal of ECronicon Gynaecology. 8(1): 21-28

Arulkumaran S, Regan L, Farquharson D, Monga A (2011). Oxford Desk Reference Obstetrics and Gynecology: 1st edition. USA: Oxford university press.

Aziz KF, Maqsood SS (2017). Self Management of Pregnant Women Regarding Minor Discomforts in Primary Health Care Centers in Erbil City. Med j Babylon. 13(2):284-293.

Bor S, Kitapcioglu GUL, Dettmar P, Baxter TIM (2007). Association of Heartburn during Pregnancy with the Risk of gastroesophageal reflux disease. Clin Gastroenterol Hepatol. 5(9): 1035-1039. https://doi.org/10.1016/j.cgh.2007.05.003

Bradley CS, Kennedy CM, Turcea AM, Rao SSC, Nygaard IE (2007). Constipation in Pregnancy: prevalence, symptoms, and risk factors. Obstet Gynecol. 110(6): 1351-1357. https://doi.org/10.1097/01.AOG.0000295723.94624.b1

Dhanawade AR (2017). A study to assess the effectiveness of planned teaching on knowledge regarding minor ailments during antenatal period among primigravida mothers in selected hospitals of Sangli city, Maharashtra, India. Int J Nurs Res. 3(2): 79-82.

Dutta DC (2004). Text book of obstetrics: India: New Central Book Agency (P) Limited.

Fraser D, Cooper M (2011). Myles' textbook for midwives: $15^{\text {th }}$ edition. London, UK: Elsevier Health Sciences.
Gamel WMA, Mohamed Fathy T, El-Nemer AMR, ShabanaKRA (2017). Utilization of Self-Care Brochure for Relieving Mother's Minor Discomforts during Pregnancy. Journal of Nursing and Women's Healthcare. 2: 108. https://doi.org/10.29011/2577-1450.100008

Jarvis S, Nelson-Piercy C (2011). Management of nausea and vomiting in pregnancy. Br Med J. 342:1407-1412.https://doi.org/10.1136/bmj.d36o6

Jewell D, Young G (2003). Interventions for nausea and vomiting in early pregnancy. UK: John Wiley and Sons Limited.

Karnati S, Vanaja Kumari B (2015). A Study to Assess the Knowledge Regarding Home Management of Minor Ailments in Pregnancy among Rural Women. Int J Recent Sci Res. 6(6): 4593-4596.

Kaur A, Gagandeep (2017). Assessment of the Knowledge and Expressed Practices Regarding Self-Management of Minor Ailments among Antenatal Mothers. IOSR Journal of Nursing and Health Science. 6(1):49-54. https://doi.org/10.9790/1959-0601014954

Latha P, Indira S (2016). Effectiveness of IEC (Information, Education and Communication) package on knowledge regarding minor ailments of pregnancy and its management among antenatal mothers at $\mathrm{NMCH}$, Nellore. Int J Appl Res. 2(10):593-596.

Maternal Care Package Sri Lanka (2011). A Guide to Field Healthcare Workers. Family Health Bureau Ministry of Health, Sri Lanka. Available at: https://medicine.kln.ac.lk/depts/publichealth/Fixe d_Learning/clearkship/3.PHM/matern al_care_package_a_guide_to_field_he althcare_workers_english.pdf,Accessed on 22nd August 2018.

Sangeetha E, Shanghais R, Revathy D (2015). A Descriptive Study to Assess the Level 
Samarakoon et al./ Knowledge and practices regarding self-management

of Knowledge on Minor Ailments in Pregnancy among Antenatal Mothers in Selected Tertiary Hospital, Kanchipuram, Tamilnadu. Journal of Nursing and Patient Safety \& Care. 1 (2):1-6.

Sharif SI, Labiadh A, Alantali MA, Rashed NA, Qatali SF, Sharif RS (2018). Know- ledge, attitude and practice of medication use during pregnancy among multiparous women in United Arab Emirates. Austin Journal of Public Health Epidemiology. 5(2): 1073. 